\title{
Discussion on the Material Factors for Falling of Face Tile
}

\author{
Wei-Ling Hsu, ${ }^{1}$ Chen-Chung Liu, ${ }^{2}$ Yan-Chyuan Shiau, ${ }^{3 *}$ \\ Chao-Lung Wang, ${ }^{4}$ and Wen-Chin Lin $^{5}$ \\ ${ }^{1}$ Huaian Key Laboratory of Geographic Information Technology and Applications, \\ School of Urban and Environmental Science, Huaiyin Normal University, \\ No. 111, ChangJang West Road, Huai'an City, Jiangsu Province 223300, China \\ ${ }^{2}$ Department of Civil Engineering, Chung Hua University, Hsinchu, \\ No. 707, WuFu Road, Section 2, Hsinchu 30012, Taiwan \\ ${ }^{3}$ Department of Landscape Architecture, Chung Hua University, Hsinchu, \\ No. 707, WuFu Road, Section 2, Hsinchu 30012, Taiwan \\ ${ }^{4}$ Department of Construction Management, Chung Hua University, Hsinchu, \\ No. 707, WuFu Road, Section 2, Hsinchu 30012, Taiwan \\ ${ }^{5}$ Department of Architecture \& Urban Planning, Chung Hua University, Hsinchu, \\ No. 707, WuFu Road, Section 2, Hsinchu 30012, Taiwan \\ (Received November 7, 2018; accepted January 21, 2019)
}

Keywords: cement mortar, face tile construction materials, cement mortar ratio, pullout intensity, temperature variation, polymer resin, falling off

Face tile installation materials mainly comprise concrete, cement mortars, an adhesive layer, face tiles, and a face tile sealing layer. Problems in any of the aforementioned parts result in a poor face tile adhesion quality. In this study, material information relevant to face tile falling was investigated, tests were planned and conducted to obtain construction variation factors, advanced sensing instruments were used to detect the health of concrete, and new materials were added to samples with low pullout values to increase the pullout values of face tiles. The results showed that the tensile strengths of the tiles were effectively improved. Thus, this method may serve as a reference to effectively reduce face tile debonding.

\section{Introduction}

\subsection{Research background}

Taiwan is located in the Ring of Fire (a seismically active zone) and at the junction of the Philippine Sea Plate and the Eurasian Plate; thus, earthquakes are frequent in Taiwan. In addition, the coastal regions of Taiwan are subject to constant weather changes. ${ }^{(1)}$ Sustainable construction is the leading reference for the design, construction, and operation of highperformance green buildings. ${ }^{(2)}$ The Life Cycle Assessment has been applied in the construction sector since the 1990s and is now continuously embedded in European public policies, e.g., for Environmental Product Declaration regulation or for building labeling schemes. ${ }^{(3)}$ Since the 1999 Jiji earthquake, people have begun to attach considerable attention to the structural safety

*Corresponding author: e-mail: ycshiau@ms22.hinet.net https://doi.org/10.18494/SAM.2019.2219 
of buildings, and related standards have been formulated and revised to compensate for previous deficiencies. However, no clear construction and related standards are in place to ensure the quality of decorative face tiles installed on building facades. This regularly results in face tiles falling off surfaces within a few years after building completion. Advanced material sensors such as chloride ion analyzers and concrete humidity monitors were applied to measure the concrete and tile cement materials to master the relevant quality of concrete, cement mortar, and adhesive. The appropriate countermeasures were explored to solve the problem of falling tiles in this study.

\subsection{Literature review}

\subsubsection{Exploring reasons of falling external wall tiles}

Architectural tiles are an important material in building facade design. ${ }^{(4)}$ Partial fill grouting may cause workmanship defects in tile grouting. ${ }^{(5)}$ An exterior tile cladding can suffer debonding or adhesive failures as it ages. ${ }^{(6)}$ Damage to external wall face tiles can be divided into two categories, which are wear-and-tear-led damage and earthquake-led damage. Similarly to the failure rates of industrial tools, the failure rates of face tiles can be represented by a bathtub curve (Fig. 1). The discontinuous nature of the core results in a nonuniform stress field under the in-plane loading of the adhesive layers. ${ }^{(7)}$ Dorokhova et al. have proposed and tested an energy-conserving technology for shrink-free face materials. ${ }^{(8)}$ In general, external wall tile damage occurs following project completion, and the causes of such damage are normally unfavorable designs, unsuitable materials, and poor construction quality. Face tile damage can be classified into four different types, namely, debonding, flaking, cracks, and stains. Of the four types of face tile damage, debonding and flaking lead to the most serious pedestrian injuries. Environmental changes, such as temperature and humidity changes, cause internal stresses within face tiles installed on walls. When this stress is greater than the adhesion

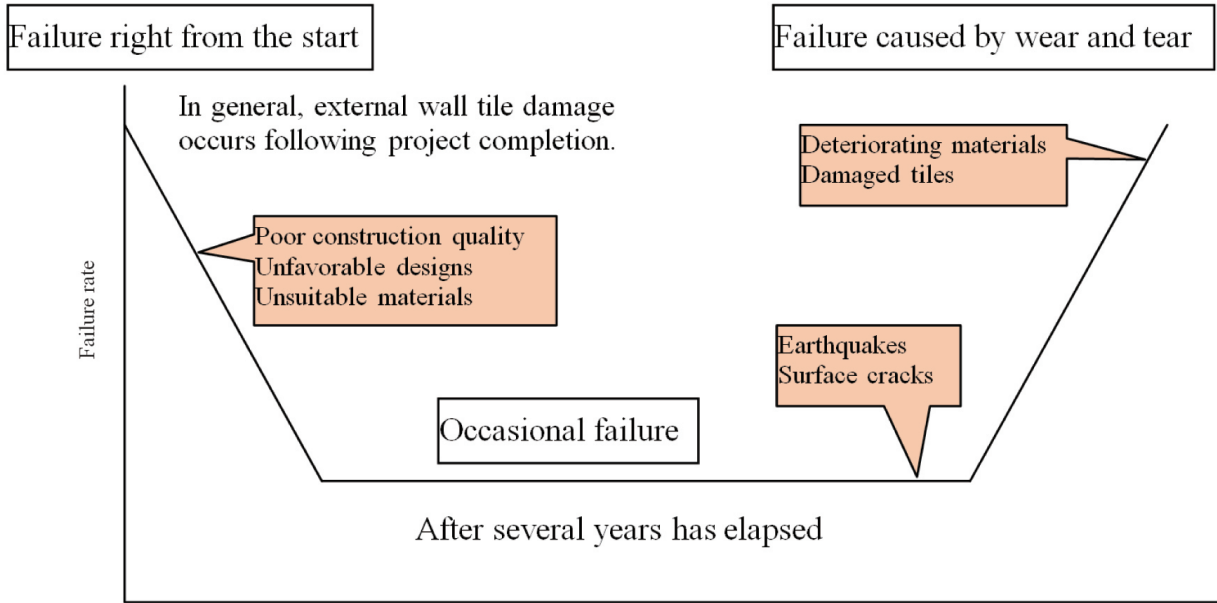

Fig. 1. (Color online) Bathtub curve. 
strength between the walls and the tile materials, peeling ensues. Face tile installations primarily comprise a concrete layer, cement mortars, an adhesive layer, face tiles, and different interfacial layers; debonding or peeling generally occurs at the interfaces of the different layers. Debonding may be further divided into the following forms (Fig. 2): ${ }^{(9)}$

A. interfacial debonding that involves cracking in the sealing layer between face tiles;

B. interfacial debonding between face tiles and adhesive;

C. interfacial debonding between adhesive and cement mortars (in the lowest layer);

D. interfacial debonding between cement mortars (in the lowest layer) and concrete.

\subsubsection{Adhesion changes in the interface joining concrete and cement mortars}

In face tile projects, the adhesive strength between concrete and cement mortars is affected by various factors, which include (1) interfacial adhesiveness, (2) interlocking effect between friction and aggregates, and (3) time. The aforementioned factors also mutually affect each other. ${ }^{(10)}$ An overview of the factors is provided as follows:

A. Interfacial adhesiveness: Interfacial adhesiveness is primarily affected by factors such as the type of adhesive used, material firmness, surface cleanliness, interface humidity, test specimen age, and surface roughness.

B. Interlocking effect between friction and aggregates: The interlocking effect between friction and aggregates is mainly affected by aggregate particle size, shape, structure, and surface conditions.

C. Time: Under normal circumstances, when cement mortars are being coated on or poured onto buildings, the concrete layer of the cement structure has already reached a contracted state. Subsequently, new layers of cement mortars poured onto the existent layers exhibit a

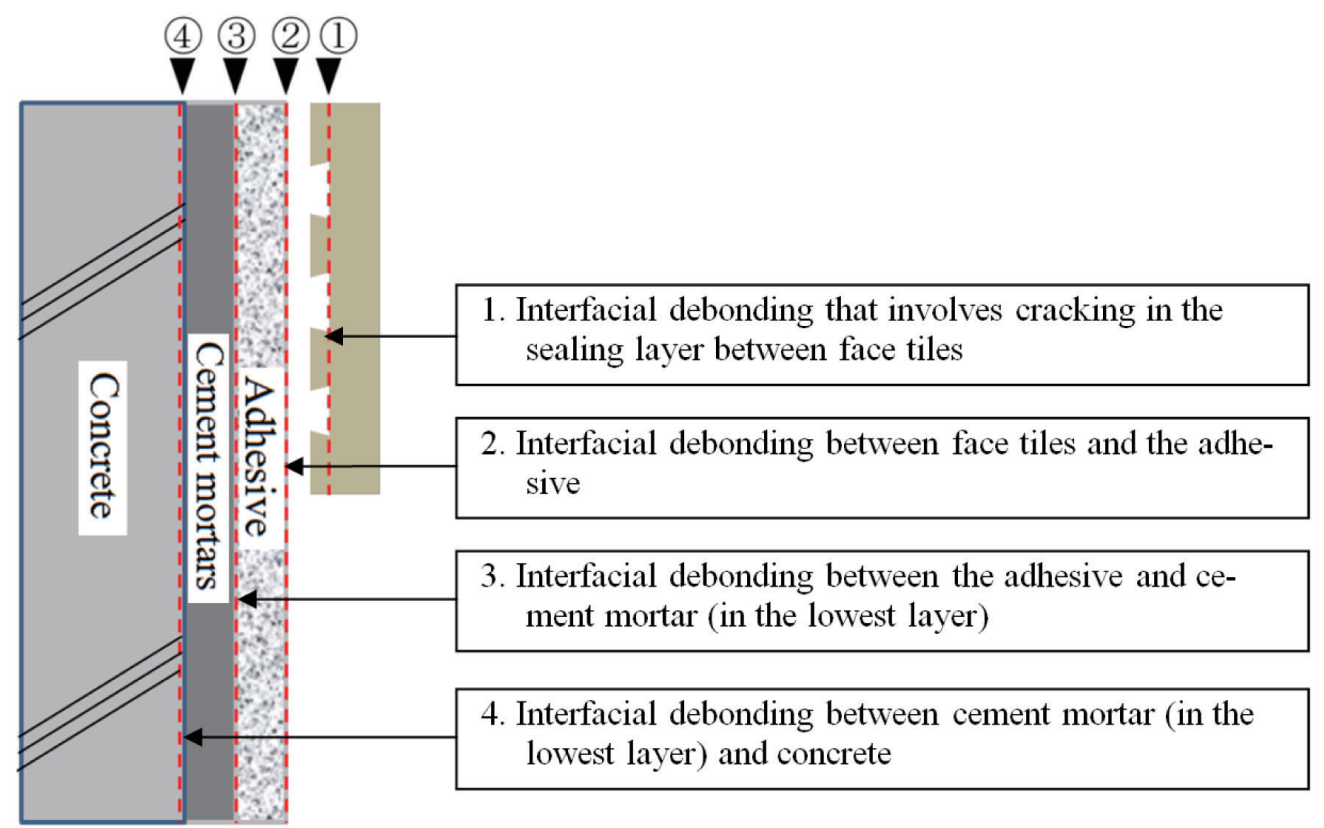

Fig. 2. (Color online) Face tile interfacial debonding. ${ }^{(12)}$ 
plastic shrinkage state. The differential shrinkage between the old and new materials results in interfacial strain, affecting interfacial adhesiveness. ${ }^{(11)}$

\subsection{Research motivation}

According to a statistical review released by the Directorate-General of Budget, Accounting, and Statistics on April 17, 2018, as of the year end of 2017, the average house age in Taiwan was 29.53 years old, a figure that showed an increasing annual trend. The average house age in Taipei City was 33.1 years, which was the oldest of the six special municipalities and indicated that Taipei City had the oldest buildings in Taiwan.

Actual construction cases have shown that, on average, tile adhesion begins to deteriorate in approximately 15-20 years. This, coupled with frequent earthquakes or large temperature variations, increases the chances of falling tile accidents. Additionally, the greenhouse effect has recently created severe climate changes, resulting in external wall tiles falling and injuring nearby pedestrians. This problem has thus raised social concerns. How to improve the outer wall tile adhesive materials to solve the tile falling problem is an important issue.

\subsection{Research objectives}

To prevent external wall tiles from falling and injuring pedestrians, in this study, we devised the following research objectives:

A. Review the literature and real-life cases to investigate the activities engaged in during the cement mortar pouring and plastering processes that lead to the subsequent falling of external wall tiles; compile the factors of influence of tile adhesion strength;

B. Conduct tests by varying certain conditions with varying conditions (e.g., changing the materials, component ratios, and weather conditions) to determine the cement mortar tensile strength levels under different conditions;

C. Add polymer resin materials to samples with low tensile strengths before running pullout tests. The results are to serve as a reference to construction units to prevent external wall tiles from falling.

The remainder of this paper is organized as follows: Sect. 2 outlines the methods, Sect. 3 details the pullout test results, Sect. 4 presents the discussion, and finally, Sect. 5 shows the conclusion.

\section{Methods}

\subsection{Fabricating compression-resistant cement mortars}

The experimental methods and materials used in this study are described as follows. In this study, the cement mortar specimens were fabricated by following the CNS1010 R3032 standard, which involved combining cement with graded standard sand at a ratio of 1 to 2.75 and combining water with Portland cement at ratios of 1:0.485. Cement-to-sand ratios of 1:3 and 1:5 
were employed to fabricate cement mortars for the lowest layer. The test specimens measured 5 $\times 5 \times 5 \mathrm{~cm}^{3}$ and the amounts of materials used are listed in Table 1 .

\subsection{Compressive strength test}

Before the compressive strength test was administered, all water was wiped from the surface of the test specimen; any debris found on the two ends of the test specimen was removed; the bearing plates of the machines were polished with sandpaper. A steel ruler was used to inspect whether the upper and lower sides of the test specimen were even before the test specimen was placed in a compressive strength testing machine. The surface of the test specimen on which force was applied had to closely match with the surface of the bearing plate, and no padding was used. The test specimen was placed below the center of the bearing plate in the test machine. The test specimen was estimated to be able to withstand $1400 \mathrm{~kg} / \mathrm{cm}^{2}$ of load; during the initial stage of the test, the load was increased at a relatively high rate before it reached half of the maximum load, after which the rate of load increase was reduced. The load margin was maintained, and the time during which the load was exerted onto the test specimen was required to last between 20 and $80 \mathrm{~s}$.

\subsection{Compressive strength data analysis}

Table 2 shows the cement mortar compressive strength data obtained from the compression tests. The tests were administered by following the CNS1010 R3032 standard. Test specimens of the same age were utilized and the averages of the results were collected; deviations between the test data and the averages were required to be $10 \%$ or less. For the first phase of the test, two different sand types (i.e., Taiwanese sand and Chinese sand) and cement mortar ratios were used, and their 7, 14, and $28 \mathrm{~d}$ maximum loads were recorded. For both sand types,

Table 1

Materials used to fabricate the cement mortar test specimens.

\begin{tabular}{lcc}
\hline Component ratio & $1: 3$ & $1: 5$ \\
\hline Cement (g) & 525 & 350 \\
Sand (g) & 1575 & 1750 \\
Water (mL, water-cement ratio 0.485$)$ & 273 & 273 \\
\hline
\end{tabular}

Table 2

Cement mortar compressive strength test results.

\begin{tabular}{lcc}
\hline Sand type + curing time (d) & $1: 3$ & $1: 5$ \\
\hline Taiwanese sand + 7 d & $361 \mathrm{~kg} / \mathrm{cm}^{2}$ & $158 \mathrm{~kg} / \mathrm{cm}^{2}$ \\
Chinese sand + 7 d & $371 \mathrm{~kg} / \mathrm{cm}^{2}$ & $160 \mathrm{~kg} / \mathrm{cm}^{2}$ \\
Taiwanese sand + 14 d & $444 \mathrm{~kg} / \mathrm{cm}^{2}$ & $191 \mathrm{~kg} / \mathrm{cm}^{2}$ \\
Chinese sand + 14 d & $427 \mathrm{~kg} / \mathrm{cm}^{2}$ & $182 \mathrm{~kg} / \mathrm{cm}^{2}$ \\
Taiwanese sand + 28 d & $500 \mathrm{~kg} / \mathrm{cm}^{2}$ & $232 \mathrm{~kg} / \mathrm{cm}^{2}$ \\
Chinese sand + 28 d & $494 \mathrm{~kg} / \mathrm{cm}^{2}$ & $221 \mathrm{~kg} / \mathrm{cm}^{2}$ \\
\hline
\end{tabular}


test specimens of the same age displayed deviations within the $10 \%$ requirement; however, Chinese sand showed a higher compressive strength in the early stage, whereas Taiwanese sand demonstrated a superior overall compressive strength in the later stage. A water-to-cement ratio of 1:5 severely hindered the compressive strengths of the cement mortar, indicating that construction sites must strictly control the water-to-cement ratios of cement mortars.

\subsection{Cement mortar pullout tests}

\subsubsection{Pullout test setup and schematic diagram}

The arrangement of the test specimens used in the cement mortar pullout tests is shown in Fig. 3 and a schematic diagram of the pullout test is shown in Fig. 4.

\subsubsection{Weather factor simulations}

In addition to concrete fracture, honeycombing, steel oxidation, holes, and release agentinduced concrete surface grease, any interfacial debonding between a cement mortar layer and concrete can directly or indirectly cause flaking. In this study, we investigated cement mortar sand sources and used various component ratios and weather (temperature) changes to facilitate
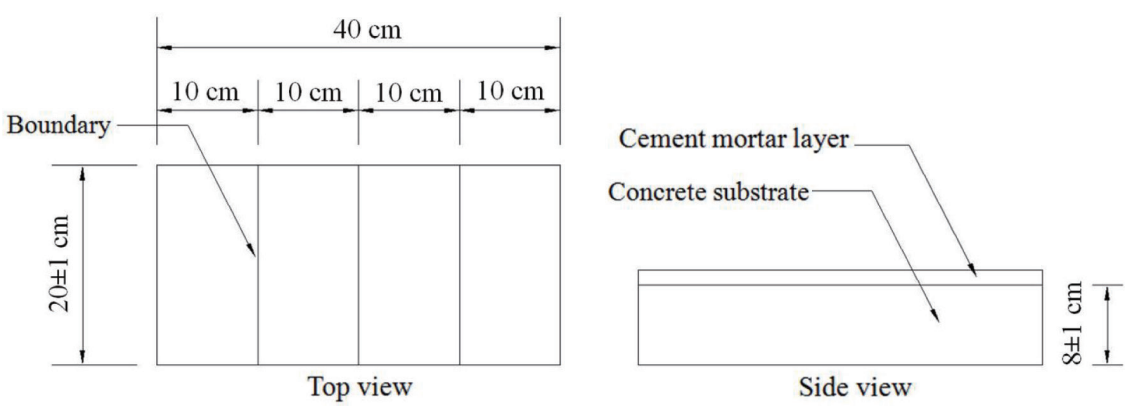

Fig. 3. Setup of the test specimens.

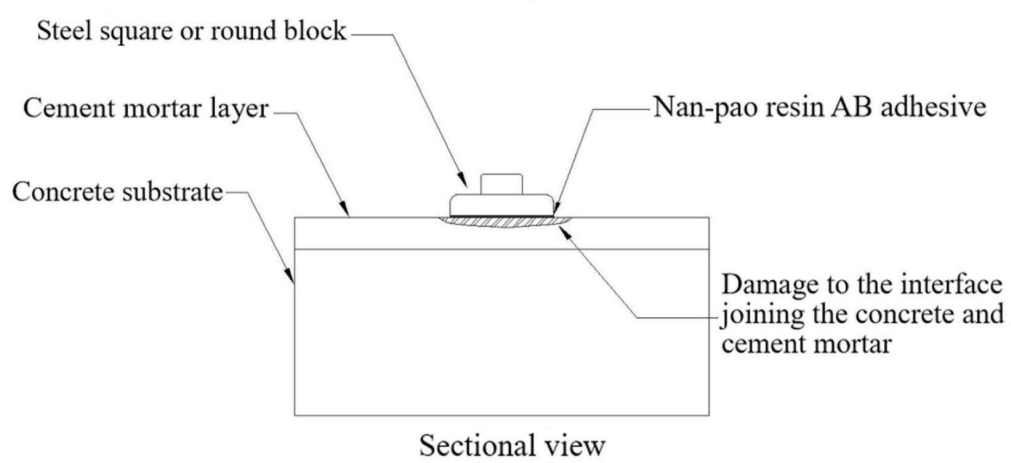

Fig. 4. Pullout test schematic diagram. 
interfacial debonding between the cement mortar layer and the concrete. When the climatic factors were simulated during the $28 \mathrm{~d}$ experiment, the test specimens were taken into closed rooms and heated using electric heaters to $38{ }^{\circ} \mathrm{C}$ or higher (i.e., the experiment temperature) whenever the daytime temperature failed to reach the required temperature. Daily temperature variations were recorded, and daily weather and temperature data provided by the Central Weather Bureau were compared with the temperatures experienced by the test specimens. For low-temperature simulations, the test specimens were placed inside refrigerators, in which the temperature was set at $8-10{ }^{\circ} \mathrm{C}$ to simulate winter temperatures in Taiwan.

\subsubsection{Manufacturing tensile-stress-resistant cement mortar test specimens}

Cement mortars used to fabricate tensile-stress-resistant test specimens are divided into two categories, namely, general cement mortars and cement mortars fortified with polymer resins. In this study, Chia Hsin cement was selected as the cement and Taiwanese sand (which contains more mud) and Chinese sand (which contains less mud) were chosen as sand samples. Onsite personnel were asked to mix the cement mortars. This study used cement mortar ratios stipulated by the Public Construction Commission (i.e., Chapter 09220: Cement Mortar Plaster), in which the cement-to-sand ratios of 1:3 and 1:5 were employed to make cement mortars for the lowest layer. For the cement mortars augmented with polymer resins, the ratio of polymer resins added was identical to that of concrete; that is, the polymer resin-to-sand ratios were also 1:3 and 1:5.

\subsubsection{Administering the pullout tests}

In this study, pullout test specimens (i.e., 16 total test specimens divided into four groups) were cemented with square and round steel plates, and maintained for approximately $1 \mathrm{~h}$ before pullout tests were conducted. At the start of the experiments, the pullout testers were affixed over the square or round blocks (Fig. 5) and manual rotational tests were performed. When the square and round steel plates peeled off from the test specimen surfaces, the pullout strengths were recorded.

\section{Results}

In this study, three types of test specimens were used in the cement mortar pullout tests. The method and result of these types are as follows:

A. Type 1: Uncracked cement mortars

A total of 16 test specimens were used, and relevant information regarding ratios and sand content was written on the surfaces of the test specimens. The square and round steel plates peeled off from the test specimen surfaces (Fig. 6); in the uncracked cement mortar samples, the steel plates peeled off the mortar layer surfaces first when pullouts were performed.

B. Type 2: Cracked cement mortars

Various factors may cause mortars to crack after hardening, which leads to decreased strengths for deep-layer cement mortar and decreased concrete pullout strengths. To 


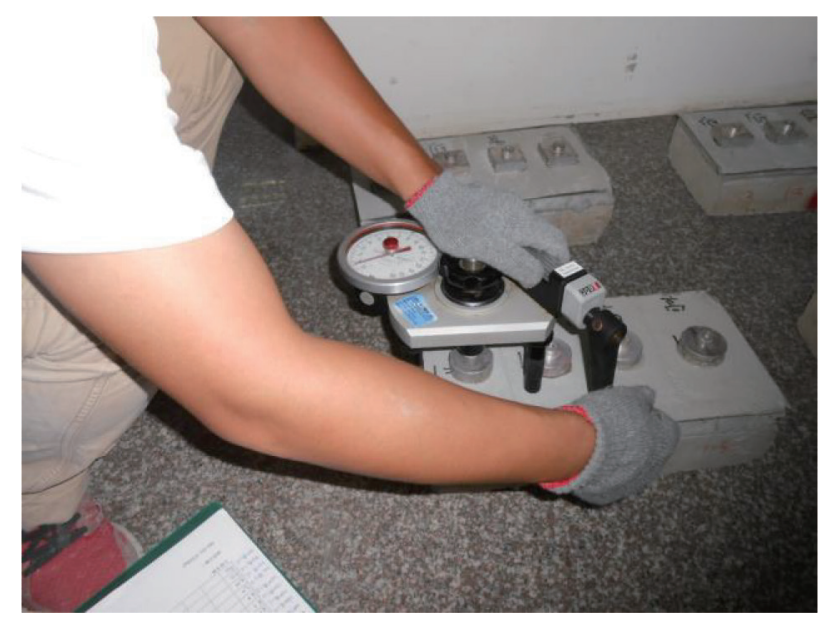

Fig. 5. (Color online) Tile pullout experiment.

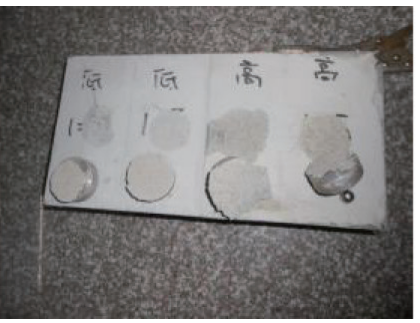

(a)

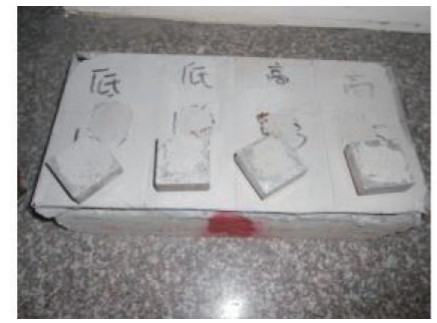

(b)

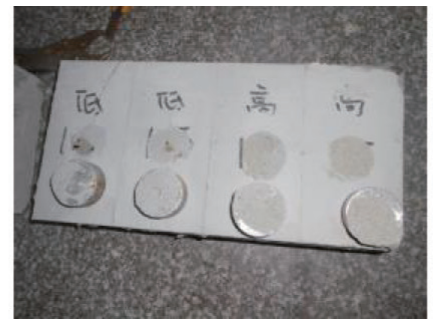

(c)

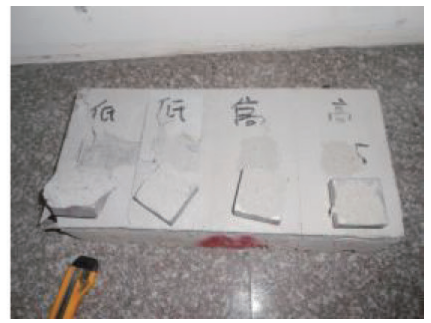

(d)

Fig. 6. (Color online) Damage to the test specimens during pullout tests. (a) Test specimen 1, (b) test specimen 2, (c) test specimen 3, and (d) test specimen 4.

simulate a cement mortar that cracks after hardening, this study used handheld grinders to cut the cement mortar specimens and affix them to square and round steel plates. The test specimens were maintained for approximately $1 \mathrm{~h}$ before pullout tests were conducted; the test results are shown in Table 3. Table 3 shows that a sufficient cement mortar thickness created high tensile strengths, whereas an insufficient cement mortar thickness created low tensile strengths and led to peeling. When other conditions were held constant, temperature variations created cracks in cement mortars, which severely reduced the cement mortar tensile strength.

C. Type 3: Cement mortars added with polymer resins

Table 3 shows that Specimens 12,14, 15, and 16 exhibited the lowest tensile strengths. However, because two cement mortar groups with a water-to-cement ratio of 1:5 had been used, 12 were replaced with 15 to represent cement mortars with a water-to-cement ratio of 1:3. In this experiment, polymer resins were added to the test specimens, which produced tensile strengths approximately two times greater than those of test specimens without polymer resins (i.e., Type 2 cement mortars; the water-to-cement ratios were kept constant). The results are shown in Table 4. 
Table 3

Type 2 test results.

\begin{tabular}{|c|c|c|c|c|}
\hline No. & Area $\left(\mathrm{cm}^{2}\right)$ & $\begin{array}{l}\text { Max. pullout } \\
\text { load }(\mathrm{kN})\end{array}$ & $\begin{array}{l}\text { Pullout resistance } \\
\text { strength }\left(\mathrm{kgf} / \mathrm{cm}^{2}\right)\end{array}$ & Notes \\
\hline 1 & 25 & 2.6 & 10.6 & Thick(3), Ratio(1:3), Sand(C), Temp(Nor) \\
\hline 2 & 25 & 1.8 & 7.3 & Thick(3), Ratio(1:5), Sand(C), Temp(Nor) \\
\hline 3 & 25 & 2.5 & 10.2 & Thick(3), Ratio(1:3), Sand(T), Temp(Nor) \\
\hline 4 & 25 & 1.7 & 6.9 & Thick(3), Ratio(1:5), Sand(T), Temp(Nor) \\
\hline 5 & 25 & 2.2 & 9.0 & Thick(1.5), Ratio(1:3), Sand(C), Temp(Nor) \\
\hline 6 & 25 & 1.7 & 6.9 & Thick(1.5), Ratio(1:5), Sand(C), Temp(Nor) \\
\hline 7 & 25 & 2.1 & 8.6 & Thick(1.5), Ratio(1:3), Sand(T), Temp(Nor) \\
\hline 8 & 25 & 1.6 & 6.5 & Thick(1.5), Ratio(1:5), Sand(T), Temp(Nor) \\
\hline 9 & 25 & 1.6 & 6.5 & Thick(3), Ratio(1:3), Sand(C), Temp(Chg) \\
\hline 10 & 25 & 1.4 & 5.7 & Thick(3), Ratio(1:5), Sand(C), Temp(Chg) \\
\hline 11 & 25 & 1.5 & 6.1 & Thick(3), Ratio(1:3), Sand(T), Temp(Chg) \\
\hline 12 & 25 & 1.3 & 5.3 & Thick(3), Ratio(1:5), Sand(T), Temp(Chg) \\
\hline 13 & 25 & 1.5 & 6.1 & Thick(1.5), Ratio(1:3), Sand(C), Temp(Chg) \\
\hline 14 & 25 & 1.2 & 4.9 & Thick(1.5), Ratio(1:5), Sand(C), Temp(Chg) \\
\hline 15 & 25 & 1.4 & 5.7 & Thick(1.5), Ratio(1:3), Sand(T), Temp(Chg) \\
\hline 16 & 25 & 1.1 & 4.5 & Thick(1.5), Ratio(1:5), Sand(T), Temp(Chg) \\
\hline \multicolumn{5}{|r|}{ (2) } \\
\hline \multirow{2}{*}{\multicolumn{3}{|c|}{$\begin{array}{l}\text { Thick(3): cement thickness: } 3 \mathrm{~cm} \\
\text { Ratio(1:3): cement-to-sand ratio: } 1: 3\end{array}$}} & \multicolumn{2}{|c|}{ Thick(1.5): cement thickness: $1.5 \mathrm{~cm}$} \\
\hline & & & Ratio(1:5): cement-to-sar & ratio: $1: 5$ \\
\hline \multicolumn{3}{|c|}{ Sand(T): Taiwan sand } & \multicolumn{2}{|c|}{ Sand(C): Chinese sand } \\
\hline \multicolumn{3}{|c|}{ Temp(Nor): Normal temperature } & \multicolumn{2}{|c|}{ Temp(Chg): Changing temperature } \\
\hline
\end{tabular}

Table 4

Type 3 test results.

\begin{tabular}{ccccc}
\hline No. & Area $\left(\mathrm{cm}^{2}\right)$ & $\begin{array}{c}\text { Max. pullout } \\
\text { load }(\mathrm{kN})\end{array}$ & $\begin{array}{c}\text { Pullout resistance } \\
\text { strength }\left(\mathrm{kgf} / \mathrm{cm}^{2}\right)\end{array}$ & Notes \\
\hline 1 & 25 & 2.8 & 11.4 & Thick(1.5), Ratio(1:5), Sand(C), Temp(Chg) \\
2 & 25 & 3.1 & 12.6 & Thick(1.5), Ratio(1:3), Sand(T), Temp(Chg) \\
3 & 25 & 2.7 & 11.0 & Thick(1.5), Ratio(1:5), Sand(T), Temp(Chg) \\
\hline
\end{tabular}

\section{Discussion}

The average house age in Taiwan is as high as 29.53 years. Owing to earthquakes and temperature difference, external wall tiles fall out and people are injured. In this paper, we discuss the causes of the detachment of external wall tiles and produce test samples through different materials, ratios, weather conditions, and so forth to obtain the tensile strength under each combination. In this study, polymer resin was added to the adhesive material to improve the adhesion between the tile and the structure to solve the fallout problem of external wall tiles.

\section{Conclusion}

In this study, different materials and methods, such as sand sources, component ratios, and weather factors, were examined to explore the causes of debonding in the interfaces joining cement mortar layers and concrete specimens. The following conclusions were drawn: 
A. Material ratio control

Most construction workers will follow the stipulated component ratio standards when mixing cement mortars; however, a few of them will increase the sand content. Therefore, onsite engineers, supervisors, and quality control personnel should pay close attention to the amount of all cement mortar-related materials used and ensure that cement mortars are stirred evenly to prevent unfavorable operations due to reduced cement mortar compressive strength.

B. Effects of various material factors on tensile strength

(a) Chinese sand showed a higher compressive strength in the early stage, whereas Taiwanese sand demonstrated a superior overall compressive strength in the later stage.

(b) A sufficient cement mortar plastering thickness yields a superior tensile strength, whereas an insufficient cement mortar plastering thickness creates a poor tensile strength. Thus, construction workers must be prevented from using insufficient quantities of cement mortar in an attempt to reduce cost.

(c) Cement mortar specimens that crack due to unfavorable weather conditions experience severe deterioration in tensile strength. Accordingly, construction workers should implement appropriate water control and ensure that construction walls are effectively shielded from strong sunlight and wind.

(d) Moderate quantities of additives (e.g., the polymer resins used in this study) can improve the tensile properties of cement mortars and ensure that the tiles are affixed appropriately and pedestrians are safe from tile falling.

C. Future research directions

This study only tested the compressive and tensile strengths of cement mortars; future studies may attempt to investigate the shear strengths of cement mortars.

\section{References}

1 Central Weather Bureau official website: http://www.cwb.gov.tw/ (accessed 25 May 2017).

2 C. J. Kibert: Sustainable Construction: Green Building Design and Delivery (Wiley, Hoboken, 2016).

3 S. Lasvaux, G. Habert, B. Peuportier, and J. Chevalier: Int. J. Life Cycle Assess. 20 (2015) 1473.

4 A. Harrison: Mater. World 21 (2013) 28.

5 S. D. Miranda, A. Palermo, and F. Ubertini: Frattura ed Integrita Strutturale 8 (2014) 293 (in Italian).

6 T. Soeta and T. Mikami: Struct. Constr. Eng. 81 (2016) 1779.

7 J. W. J. Gillespie, L. A. Carlsson, A. A. Gawandi, and T. A. Bogetti: Comp. Struct. 94 (2012) 3186.

8 E. Dorokhova, F. Zhernovoi, N. Zhernovaya, I. Izotova, V. Bessmertnyi, and E. Tarasova: Glass Ceram. 73 (2016) 103.

9 O. Kazuhiro: Proc. Workshop on Durability Diagnoses and Maintenance Technologies of External Wall Tiles (2007).

10 A. Momayez, A. A. Ramezanianpour, H. Rajaie, and R. E. Mohammad: ACI Matel. J. 101 (2004) 99. https://www.concrete.org/publications/internationalconcreteabstractsportal. aspx $? \mathrm{~m}=$ details $\& \mathrm{ID}=13045 \& \mathrm{~m}=$ details $\& I D=13045$

11 W. T. Lee: Adhesive Materials of the Tile Project, Master Thesis, Department of Civil Engineering, National Taipei University of Technology Taipei (2005).

12 Perma Enterprise Co., Ltd.: Statistical Survey on Tile Debonding/Flaking. http://www.perma.com.tw/zh-tw/ (accessed 29 October 2018) (in Chinese). 


\section{About the Authors}

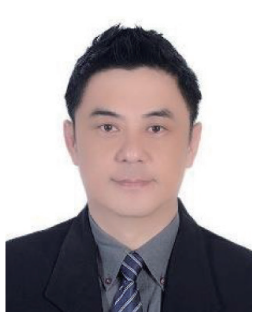

Wei-Ling Hsu received his Ph.D. degree in 2014 from the Department of Civil Engineering and his Master's degree in architecture in 2009 from Chung Hua University in Taiwan. From 2009 to 2017, he served as an adjunct assistant professor at Chung Hua University and Minghsin University of Science and Technology. He is currently serving at the Huaian Key Laboratory of Geographic Information Technology and Applications, School of Urban and Environmental Science, Huaiyin Normal University, China. His research expertise includes the application of satellites and unmanned aerial vehicles in ground-level environmental monitoring, urban traffic, urban and rural planning, and the incorporation of data analysis in fuzzy multiple criteria decision making for cities and environments.

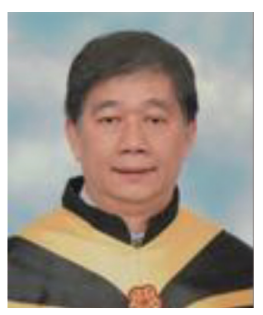

Chen-Chung Liu received his B.S. and M.S. degrees from Chung Hua University Taiwan, in 2014 and 2016, respectively. He has been a Ph.D. student in Chung Hua University, Taiwan since 2016. His research interests are in reducing working hours, extending building life, and environmental protection.

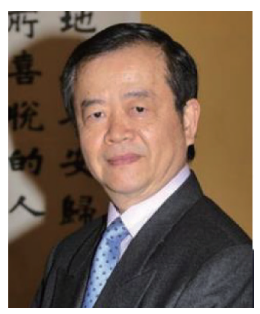

Yan-Chyuan Shiau received his B.S. degree from National Taiwan Institute of Technology, Taiwan, in 1980 and his M.S. and Ph.D. degrees from Texas A\&M University, U.S.A., in 1988 and 1992, respectively. From 2000 to 2012, he was an associate professor at Chung Hua University, Taiwan. Since 2013, he has been a professor at Chung Hua University, Taiwan. His research interests are in ICT, IoT, and smart home.

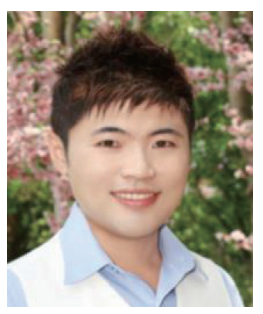

Chao-Lung Wang received his B.S. degree from Nan Kai University of Technology, Taiwan, in 2004. He received his M.S. degree from Chung Hua University, Taiwan, in 2017. He is currently a site manager in Guan-Jou Construction Company. His research interests are in construction management and project administration.

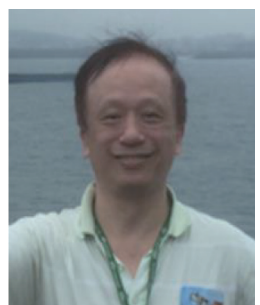

Wen-Chin Lin received his M.S. and Ph.D. degrees from the University of Minnesota, U.S.A., in 1990 and 1996, respectively. He has been an associate professor at Chung Hua University, Taiwan since 1996. His research interests are in urban and building disaster prevention, environmental impact assessment, building energy conservation, and rainwater utilization. 